\title{
Performance Assessment of Shell and Tube Heat Exchanger in an Ammonia Plant
}

\author{
Ahmed Isah, John.I Sodiki, Barinyima Nkoi
}

\begin{abstract}
The main objective of this work is to assess the performance of two heat exchanger units (Stripper/Gas Overhead Condenser and Methanator Effluent Cooler) operating under steady state conditions in two stages. Two different methods are employed in monitoring the heat exchanger fouling, namely dirt factor trend method and a statistical control technique where a Cumulative Sum (CuSum) chart is used to check the stability of the process. Data were obtained through steady state monitoring and direct measurements from the plant. The data were analyzed using various energy equations and a computer program to determine the overall heat transfer coefficient, heat duty, capacity ratio, corrected log-mean-temperature difference, fouling factor, temperature range of both fluids and effectiveness. The result shows that for the Stripper/Gas Overhead Condenser, the overall heat transfer coefficient was $63.13 \%$ less than the design value in stage 1 and $12.59 \%$ less in stage2. For the Methanator Effluent Cooler the value of heat duty and the overall heat transfer coefficient were $51.76 \%$ and $59.62 \%$ less respectively than the design value in stage 1 and $30.72 \%$ and $30.16 \%$ less respectively in stage 2 . This was traceable to increase in heat transfer rate as a result of injecting the tubes of the exchangers with NALCO fluid. In order to detect small changes in the heat exchanger operation and to know the actual time fouling starts to build up, a Cusum chart is used. This work made use of QI Macros software to check the stability of the heat exchanger units and to know if processes are on-target.
\end{abstract}

Index Terms-Effectiveness, CuSum, fouling, NALCO, micro-biocide, capacity-ratio.

\section{INTRODUCTION}

A heat exchanger is a device that is used to transfer thermal energy between two fluids, between a solid surface and a fluid, or between solid particulates and a fluid, at different temperatures and in thermal contact [6]. Typical applications of this equipment are to recover heat or reject heat, sterilize, pasteurize, distil, fractionate, concentrate, crystallize or control a process fluid under certain conditions [12].

The most commonly used type of heat exchanger is the Shell-and-Tube Heat Exchanger (STHE). It provides a relatively larger amount of heat transfer per unit volume and can be designed to meet almost any heat transfer service [15]. The equipment allows energy in the plant to be passed from one process fluid to another in a controlled manner and can be used for temperature profile control as well as steam generation and phase separation [8]. It is widely recommended for high temperature service as it can accommodate thermal expansion [1].

A decrease in the heat transfer rate can be caused by corrosion, crystallization and polymerization initiated when certain unsaturated compounds are heated with a hot surface, forming carbonaceous deposits such as coke and tar. The surface deposit or microbial formation in the inner and outer surface is known as fouling. The surface deposit in the heat exchanger increases the thermal resistance and lowers the performance of the equipment [11]. Other factors that will also affect the exchanger performance are the temperature difference between the two fluids, flow rate, nature of the conducting materials and the surface area of the heat exchange [10].

This paper evaluates the thermal assessment of two different shell-and-tube heat exchangers (1110-C and 115C) at the region of carbon (IV) oxide absorption and methanation in two stages. The first stage is when the heat exchangers are operating under normal working conditions until fouling is suspected, while the second stage is when a solution (NALCO 7330) is injected into the tubes of the heat exchangers. A statistical control technique is also employed in the assessment process in order to know the ideal instant to stop operation and clean the heat exchangers.

When a heat exchanger is noticeably fouled, a solution of NALCO 7330 is injected into the tubes of the heat exchanger. Thus, for every 3800 liters of water in the system about $1.116 \mathrm{~kg}$ to $3.384 \mathrm{~kg}$ of NALCO 7330 solution is needed. The solution contains 5-Chloro-2-methyl-4isothiazolin-3-one (1.1\%), 2-methyl-4-isothiazolin-3-one $(0.4 \%)$ and inert ingredient (98.5\%) [9].

In a shell and tube heat exchangers, the cooling water flows through the tube side and the steam enters the shell side where condensation occurs on the outside of the heat transfer tube [5]. On the contrary, vapor can be passed through the tubes with the coolant water flowing around the outside.

Ammonia production involves several stages. These stages are grouped into two primary operations: the reforming and the synthesis processes [2]. As shown in fig. 2 , the ammonia reforming takes a feed of natural gas and steam. The system under consideration comprises of two streams in need of heating or cooling. The hot stream runs from the secondary reformer to the absorber at a pressure of 35.29bar. It takes a vapor stream consisting mainly steam, hydrogen and nitrogen with small amounts of carbon (II) oxide, carbon (IV) oxide, methane and argon. It requires cooling from $995.80 \mathrm{C}$ to $2500 \mathrm{C}$. The cold stream is the combined feed of methane and steam that needs to be heated before entering the primary reformer. It constitutes steam and methane, with traces of carbon (IV) oxide and nitrogen gas and it must be heated from $231.10 \mathrm{C}$ to $600 \mathrm{oC}$ at $39.22 \mathrm{bar}$ 


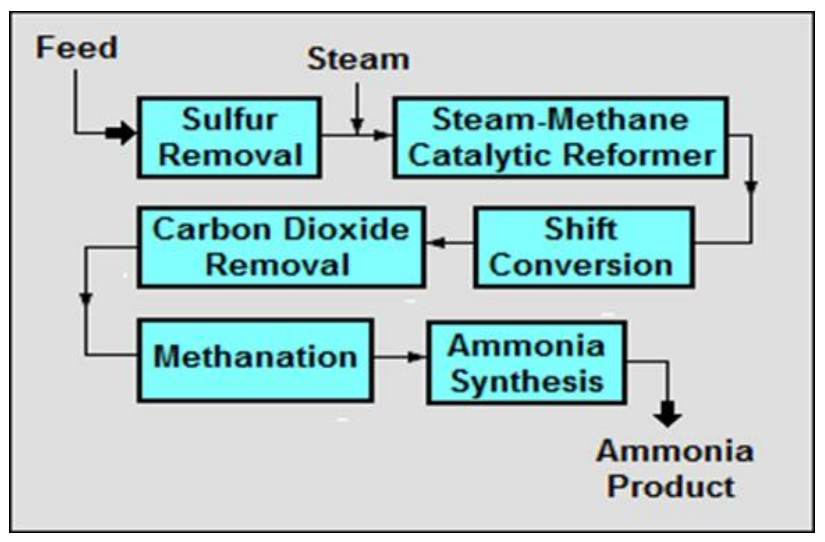

Fig. 1. Proccess flow diagram of ammonia production.

\section{MATERIAL AND METHODS}

\section{A. Thermal Analysis}

The thermal analysis of a shell-and-tube heat exchanger involves the determination of the heat transfer coefficient from the individual film coefficients [7]. A suitable method for assessing the thermal performance of a shelland-tube heat exchanger is the dirt factor trend.

\section{B. Dirt Factor Trend}

Dirt factor also known as fouling factor reveals how well the exchanger is performing with reference to its design. The smaller the dirt factor, the smaller the fouling in the heat exchanger, hence the higher the effectiveness of the heat exchanger.

Dirt factor $(\mathrm{Rd})$ is computed from process stream data by using the equation [14]

$R_{d}=\frac{U_{c}-U_{d}}{U_{d} U_{c}}$

where

$U_{d}$ is the dirty overall heat transfer coefficient, $\mathrm{W} / \mathrm{m}^{20} \mathrm{C}$

$\mathrm{U}_{\mathrm{c}}$ is the Clean overall heat transfer coefficient, $\mathrm{W} / \mathrm{m}^{2}{ }^{0} \mathrm{C}$

\section{Overall Dirty Coefficient $U_{d}$}

$U_{d}=\frac{Q_{a}}{A F_{c} \Delta T_{l m}}=\frac{Q_{a}}{A \Delta T_{l C}}$

where

$\mathrm{Q}_{\mathrm{a}}$ is the Actual heat duty, Kw;

$A$ is the surface area, $\mathrm{m}^{2}$;

$\mathrm{F}_{\mathrm{c}}$ is the correction factor,

$\Delta T_{l m}$ is log-mean-temperature-difference

and $\Delta T_{l C}$ is the corrected log-mean-temperature-difference.

The Heat duty, $Q_{a}$ is define as:

$Q_{a}=\frac{Q_{h}+Q_{c}}{2}$
$Q_{c}=\dot{m}_{c}\left(h_{c, i}-h_{c, o}\right)=\dot{m}_{c} c_{p c}\left(T_{c, i}-T_{c, o}\right)$

where

$\mathrm{Q}_{\mathrm{h}}$ and $Q_{c}$ are heat duty of hot and cold streams respectively, $\mathrm{kw}$

$\dot{\mathrm{m}}_{\mathrm{h}}$ and $\dot{\mathrm{m}}_{\mathrm{c}}$ are the mass flow rate of hot and cold fluid, $\mathrm{kg} / \mathrm{s}$ $h_{h, i}$ and $h_{h, o}$ are the enthalpy inlet and outlet of hot fluid, $k J$ $h_{c, i}$ and $h_{c, o}$ are the enthalpy inlet and outlet of cold fluid, $k J$

\section{Log-Mean Temperature-Difference $\left(\Delta T_{l c}\right)$}

with correction factor $F_{c}$ can be determined using the correlation [11]

$\Delta T_{L C}=\frac{\theta_{1}-\theta_{2}}{l_{n}\left(\theta_{1 / \theta_{2}}\right)} F_{C}$

where

$\theta_{1}$ is the difference between the outlet values hot and cold fluids $\theta_{2}$ is the difference between the inlet values of hot and cold fluids

$\theta_{1}=T_{h i}-T_{c o}$ and $\theta_{2}=T_{h 0}-T_{c i}$

$\mathrm{T}_{\mathrm{hi}}$ and $\mathrm{T}_{\mathrm{ho}}$ are the temperature inlet and outlet of hot fluid.

$\mathrm{T}_{\mathrm{ci}}$ and $\mathrm{T}_{\mathrm{co}}$ are the temperature inlet and outlet of cold fluid.

$F_{c}$ can be obtain graphically or by using the correlation of Bowman et al (7).

$F_{C}=\frac{\sqrt{R^{2}+1} \operatorname{In}\left(\frac{1-X}{1-R X}\right)}{(R-1) \operatorname{In}\left\{\frac{\frac{2}{X}-1-R+\left(\sqrt{R^{2}+1}\right)}{\frac{2}{}^{-1-R}-\left(\sqrt{R^{2}+1}\right)}\right\}}$

where $X=\frac{1-\left(\frac{R P-1}{P-1}\right)^{\frac{1}{N p}}}{R-\left(\frac{R P-1}{P-1}\right)^{\frac{1}{N p}}}$

when $\mathrm{R}=1$

$F_{C}=\frac{\left(\frac{P \sqrt{2}}{1-P}\right)}{\operatorname{In}\left\{\frac{2-P(2-\sqrt{2})}{2-P(2+\sqrt{2})}\right\}}$

where $\mathrm{R}=$ Capacity ratio and $\mathrm{P}=$ Effectiveness

For 1-1 shell and tube heat exchanger, $\mathrm{F}_{\mathrm{c}}=1$

$R=\frac{\text { Temp.drop in hot fluid }}{\text { Temp.rise in cold fluid }}=\frac{T_{h 1}-T_{h 2}}{T_{c 2}-T_{c 1}}=\frac{C_{c}}{C_{h}}=\frac{\left(m_{c p}\right)_{c}}{\left(m_{c p}\right)_{h}}$

$P=\frac{\text { Cold fluid temp.range }}{\text { Inlet Temp. diff. bw hot and cold fluid }}=\frac{T_{c 2}-T_{c 1}}{T_{h 1}-T_{c 1}}$

\section{E. Overall Clean Heat Transfer Coefficient $U_{c}$}

$\mathrm{U}_{\mathrm{c}}$ can be computed using the relationship in [15]

$U_{c}=\left[\frac{D_{o}}{h_{i} D_{i}}+D_{o} \frac{\ln \left(\frac{D_{o}}{D_{i}}\right)}{2 k}+\frac{1}{h_{o}}\right]-1$ 
where

$\mathrm{D}_{\mathrm{i}}$ and $\mathrm{D}_{\mathrm{o}}$ are the inlet and outlet diameter of the tube, $\mathrm{m}$. $\mathrm{k}$ is the thermal conductivity of the material, $\mathrm{W} / \mathrm{m}^{\circ} \mathrm{k}$.

$h_{i}$ and $h_{o}$ of Heat-transfer coefficient for inner and outside (tube-side) fluid, $\mathrm{W} / \mathrm{m}^{2} \mathrm{k}$

$\mathrm{h}_{\mathrm{i}}$ can be computed using the correlation [15]

$h_{i}=\frac{4200(1.35+0.02 T) U_{t}^{0.8}}{D_{i}^{0.2}}$

$\mathrm{h}_{\mathrm{o}}=\exp (-0.665+$

$\left.0.5195 \operatorname{In}\left(\frac{D_{c} G_{S}}{u}\right)\right)\left(\frac{k}{D_{e}}\right)\left(\left(\frac{c \mu}{k}\right)^{1 / 3}\right)\left(\left(\frac{\mu}{\mu_{w}}\right)^{0.14}\right)$

where $D_{e}$ is the equivalent diameter

$\mathrm{G}_{\mathrm{s}}$ is the mass velocity of shell-side.

For triangular pitch,

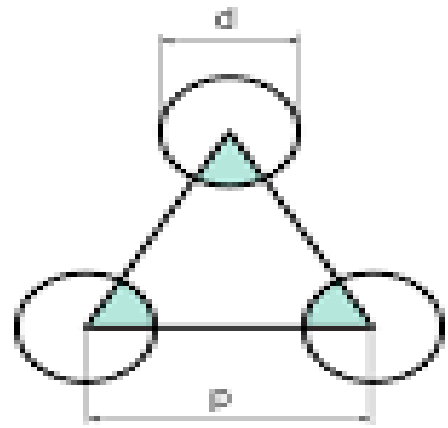

Fig. 2. Tube Layout

$D_{e}=\frac{1.1}{D_{o}}\left(P_{t}^{2}-0.917 D_{t}^{2}\right)$

$G_{S}=\frac{\dot{\mathrm{m}}_{S}}{A_{s}}$

where $A_{S}$ is the cross flow area

$\mathrm{A}_{\mathrm{S}}=\frac{\left(\mathrm{P}_{\mathrm{t}}-D_{o}\right) \times D_{S} \times B}{\mathrm{P}_{\mathrm{t}}}$

$P_{t}$ is the Tube pitch, $m$, and $B$ is the baffle spacing, $m$.

Hence, knowing the overall dirty coefficient and clean coefficient, then the dirt factor can be computed. For monitoring purpose we can either plot the dirt factor-time period or the reciprocal of the dirt factor against time (months).

The performance of the exchangers under investigation is said to be normal if the dirt factor remains below the design value over the monitoring period.

\section{F. Cumulative Sum (CUSUM) Control Charts}

When analyzing the overall quantity, the average value of parameters is calculated over a window of specific length, which is selected in accordance with the process being studied, and the CUSUM Chart is used to monitor the average value of the parameters for a shift from their reference value. From fig. 2, if the average value is not changing in time, it is said to be under control. If on the other hand, there is a shift in the average value, it is said to out of control. If the process remains in control the cumulative sum should fluctuate around zero. If there is a shift in the value of the parameters, either upward or downward, the CUSUM Chart should pick it up quickly. An upward movement indicates positive shift, while a downward movement denotes negative shift.

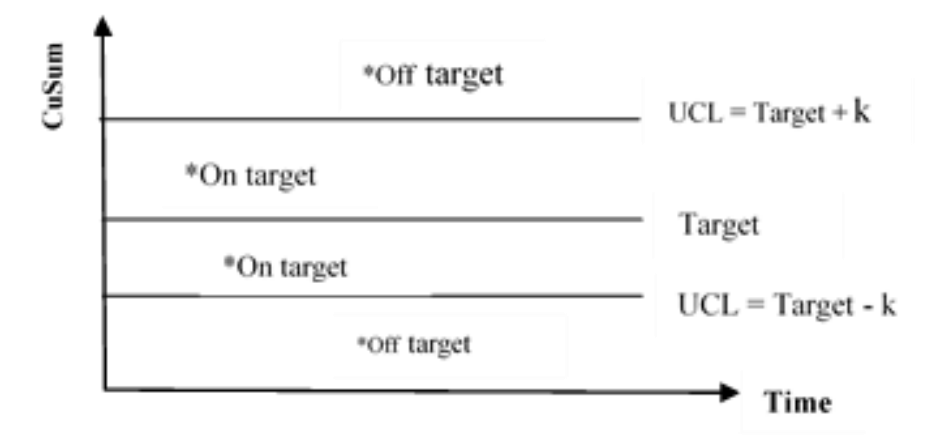

Fig. 3. CUSUM Chart [3]

\section{RESULTS AND DISCUSSION}

\section{A. Thermal Analysis}

The results for the two co-current heat exchanger units: $\mathrm{C} 02$ - Stripper gas Overhead condenser and Methanator Effluent Cooler are obtained by inputting the measured values into equation (1) - (17)

i. Performance assessment of CO2 Stripper/Gas Overhead Condenser (1110-C)

Table I shows a comparison of calculated data between the two stages and also with the design values for the heat exchanger unit. 
TABLE I: TABLE 1 COMPARISON BETWEEN STAGE 1 AND STAGE 2 FOR 1110-C

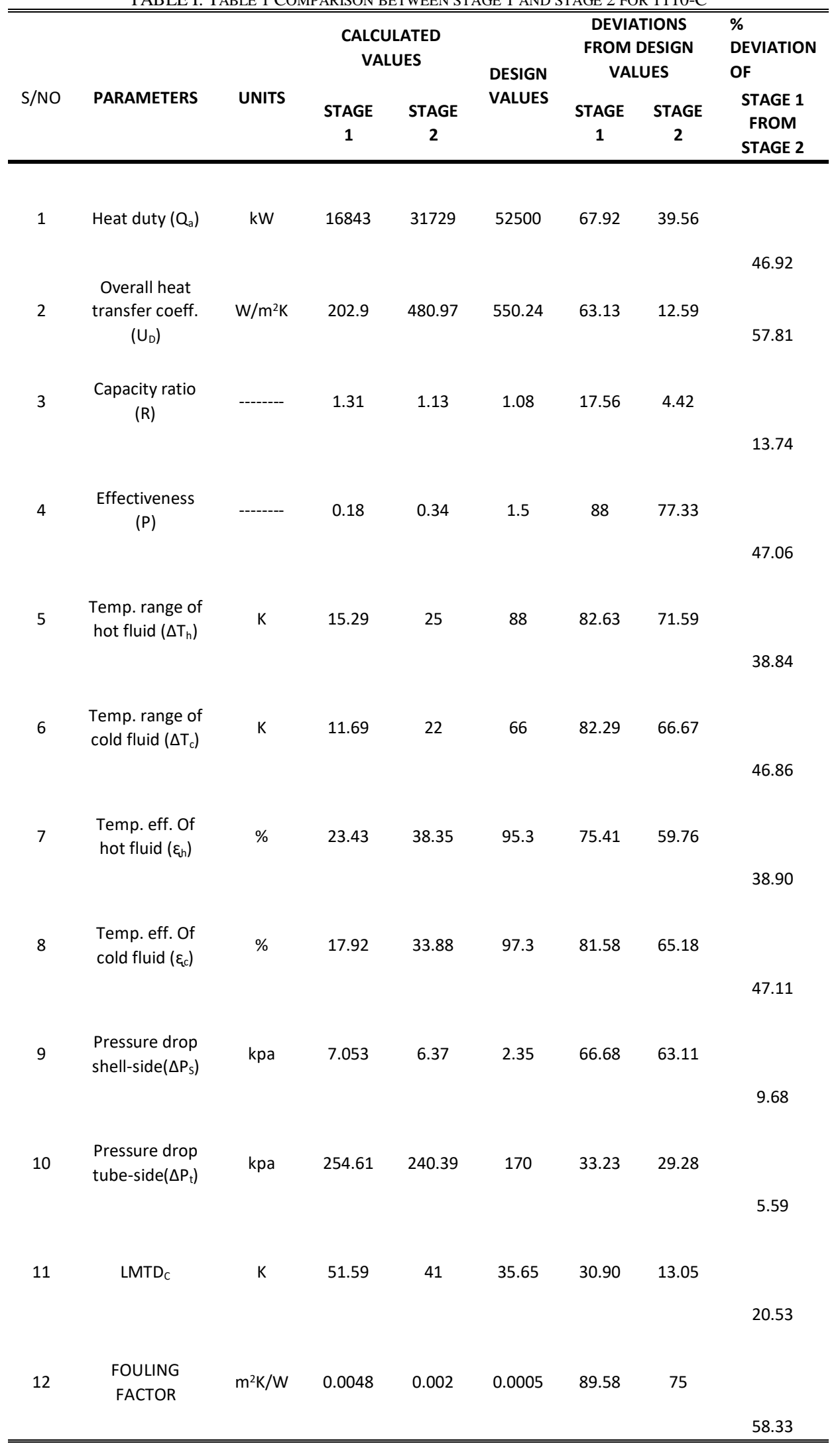

From Table I, it is observed that the heat duty of 1110-C in stage 1 increases by $46.92 \%$ in stage 2 . It is also observed that the heat duty in stage 1 is $67.92 \%$ less than that of the designed value while in stage 2 it is $39.56 \%$ less than the design value. The fouling factor $0.0048 \mathrm{~m} 2 \mathrm{k} / \mathrm{W}$ in the first stage reduces to $0.002 \mathrm{~m} 2 \mathrm{k} / \mathrm{W}$ in the second stage showing a deviation of $58.33 \%$ from the second stage and also a deviation of $89.58 \%$ from the design value. These differences could be because of the specific heat capacity deviation with temperature or the heat loss due to radiation from the hot shell of the heat exchanger unit. The assessment effect of the controlled parameters on the technical performance of the heat exchanger unit 1110-C 
can be simplified through graphical representation using QI

Macros software as shown in Fig. 4 and 5.

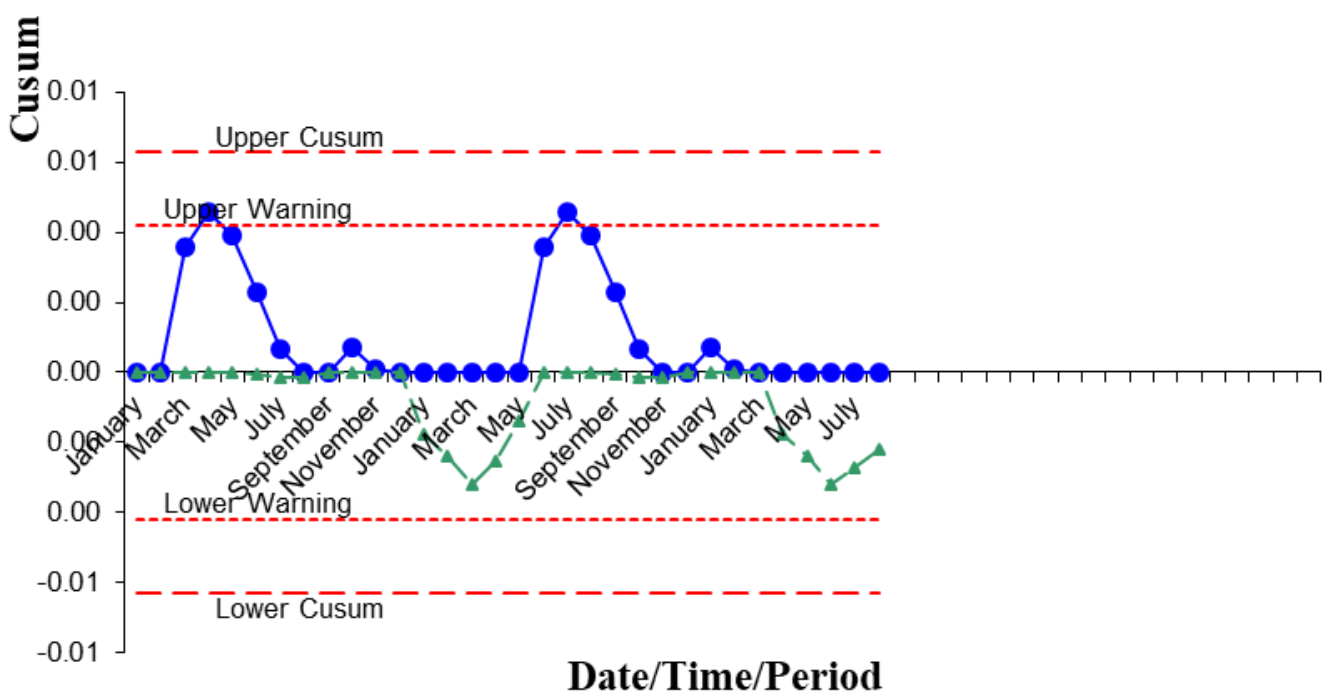

Fig. 4. Variation of Overall Fouling Resistance over Time in months (1110-C) for Stage 1

From Fig. 4 it is observed that there is stability in process since all the plotted points are within the Upper and Lower Cusum. However, at the month March and July the Cusum chart will trigger a warning alarm indicating the presence on unwanted deposit.

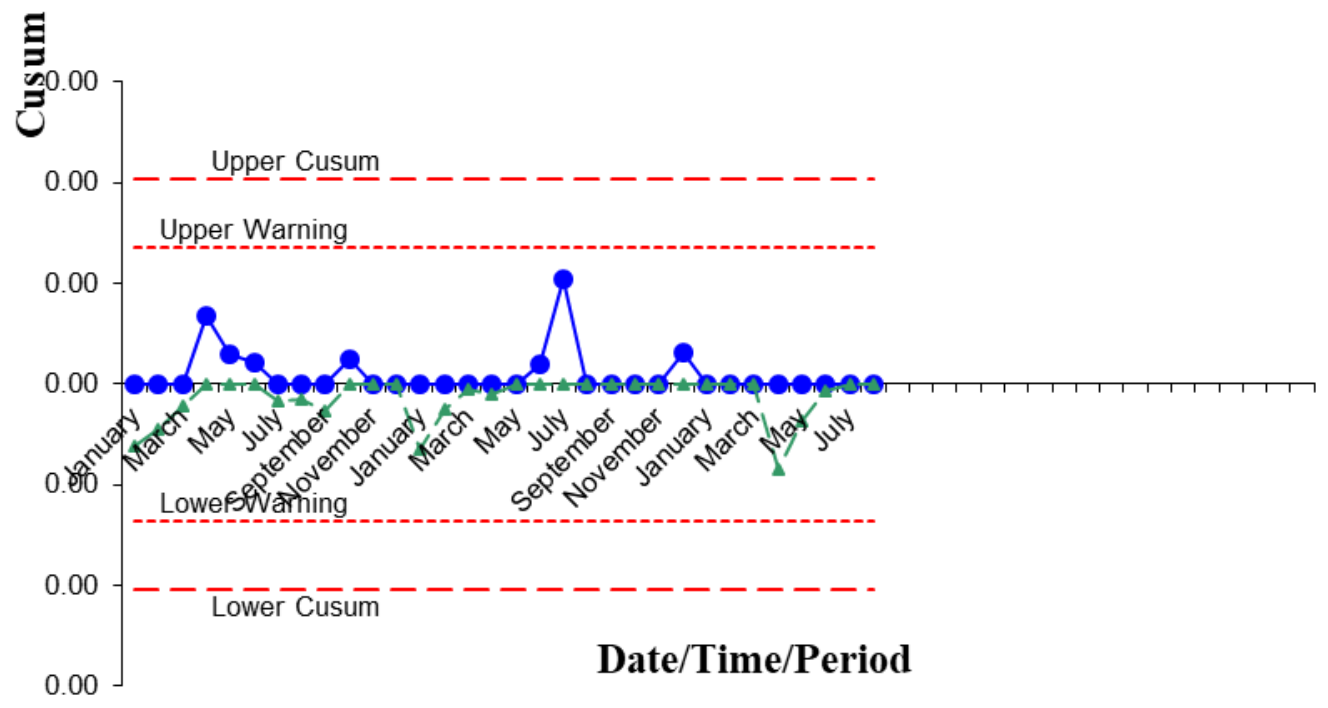

Fig. 5. Variation of Overall Fouling Resistance over Time in months (1110-C) for Stage 2

From Fig. 5, it will be observe that the plotted point fluctuate around the zero line on the Cusum chart. This could be because of a decrease in the pressure drop in the tube-side of the heat exchanger (1110-C). The chart also shows a high level decrease in the fouling factor.

\section{ii. Performance assessment of Methanator Effluent Cooler (115-C)}

Table II shows a comparison of calculated data between the two stages and also with the design values for the heat exchanger unit. From Table II, it is observed that the heat duty of $115-\mathrm{C}$ in stage 1 increases by $30.72 \%$ in stage 2 . It is also observed that the heat duty in stage 1 is $51.76 \%$ less than that of the designed value while in stage 2 there is a $30.72 \%$ from the design value. The fouling factor in the first stage reduces by $85.29 \%$ over that of the design in stage 1 and reduces to $73.68 \%$ in stage 2 . These differences could be because of the specific heat capacity deviation with temperature or the heat loss due to radiation from the hot shell of the heat exchanger unit. 
TABLE II CALCULATED VALUES OF PARAMETERS IN 115-C FOR STAGE 1 AND STAGE 2

\begin{tabular}{|c|c|c|c|c|c|c|c|}
\hline \multirow[b]{2}{*}{$\mathrm{S} / \mathrm{NO}$} & \multirow[b]{2}{*}{ PARAMETERS } & \multirow[b]{2}{*}{ UNITS } & \multicolumn{2}{|c|}{ CALCULATED VALUES } & \multirow{2}{*}{$\begin{array}{l}\text { DESIGN } \\
\text { VALUES }\end{array}$} & \multicolumn{2}{|c|}{ DEVIATIONS } \\
\hline & & & STAGE 1 & STAGE 2 & & STAGE 1 & STAGE 2 \\
\hline 1 & Heat duty $\left(Q_{a}\right)$ & $\mathrm{kW}$ & 31.503 & 45.243 & 65.3 & 51.76 & 30.72 \\
\hline 2 & $\begin{array}{c}\text { Overall heat } \\
\text { transfer coeff. } \\
\left(U_{D}\right)\end{array}$ & $\mathrm{W} / \mathrm{m}^{2} \mathrm{~K}$ & 290.81 & 503.05 & 720.3 & 59.62 & 30.16 \\
\hline 3 & $\begin{array}{c}\text { Capacity ratio } \\
(\mathrm{R})\end{array}$ & -------- & 3.28 & 2.26 & 1.25 & 61.89 & 44.69 \\
\hline 4 & $\begin{array}{c}\text { Effectiveness } \\
\text { (P) }\end{array}$ & -------- & 0.18 & 0.26 & 1.2 & 0.85 & 78.33 \\
\hline 5 & $\begin{array}{l}\text { Temp. range of } \\
\text { hot fluid }\left(\Delta T_{h}\right)\end{array}$ & $\mathrm{K}$ & 70.96 & 81.62 & 95.5 & 25.7 & 14.53 \\
\hline 6 & $\begin{array}{l}\text { Temp. range of } \\
\text { cold fluid }\left(\Delta T_{c}\right)\end{array}$ & $\mathrm{K}$ & 21.65 & 31.2 & 43.8 & 50.57 & 28.77 \\
\hline 7 & $\begin{array}{l}\text { Temp. eff. Of } \\
\text { hot fluid }\left(\varepsilon_{h}\right)\end{array}$ & $\%$ & 60.37 & 69.27 & 98.5 & 38.71 & 29.68 \\
\hline 8 & $\begin{array}{l}\text { Temp. eff. Of } \\
\text { cold fluid }\left(\varepsilon_{c}\right)\end{array}$ & $\%$ & 18.42 & 26.48 & 85.9 & 78.56 & 69.17 \\
\hline 9 & $\begin{array}{l}\text { Pressure drop } \\
\text { shell-side }\left(\Delta P_{S}\right)\end{array}$ & kpa & 36.72 & 82.82 & 10.5 & 71.41 & 87.32 \\
\hline 10 & $\begin{array}{l}\text { Pressure drop } \\
\text { tube-side }\left(\Delta P_{t}\right)\end{array}$ & kpa & 0.19 & 0.12 & 0.052 & 72.63 & 56.67 \\
\hline 11 & LMTD $_{C}$ & $\mathrm{~K}$ & 67.33 & 55.9 & 85.35 & 21.11 & 34.5 \\
\hline 12 & $\begin{array}{l}\text { FOULING } \\
\text { FACTOR }\end{array}$ & $\mathrm{m}^{2} \mathrm{~K} / \mathrm{W}$ & 0.0034 & 0.0019 & 0.0005 & 85.29 & 73.68 \\
\hline
\end{tabular}




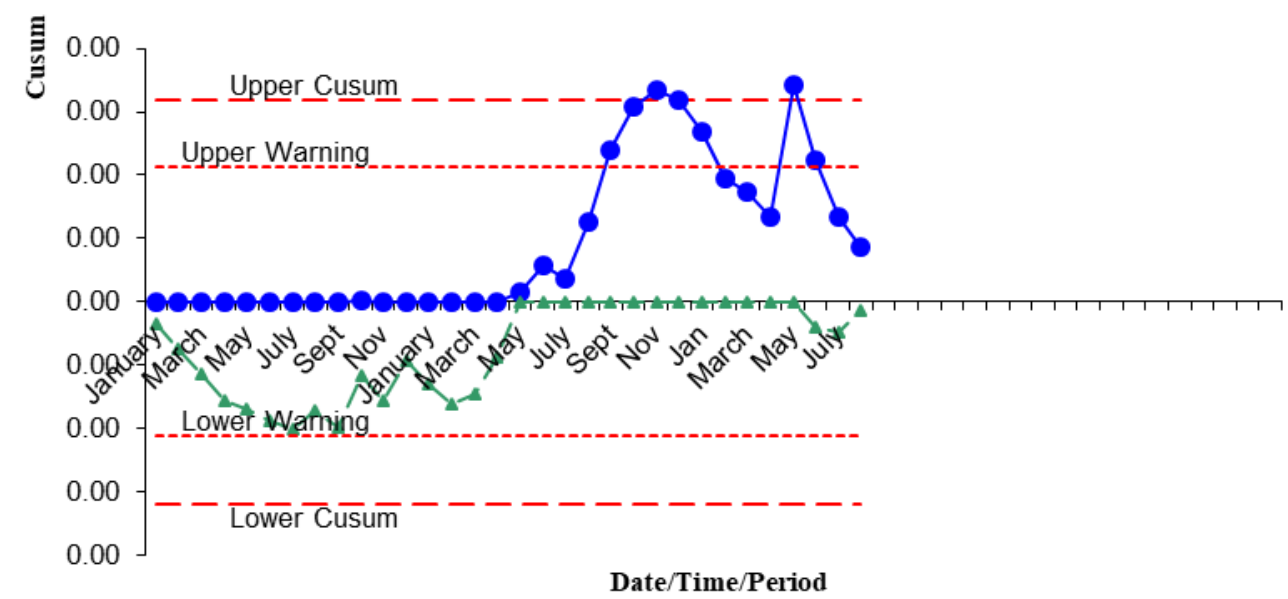

Fig. 6. Variation of Rd over Time in Months (115-C) for Stage 1

From Fig. 6 it is observed that there is a significant quickly pick it up. At this stage1 the fouling level is quit change in the process performance and the Cusum chart high.

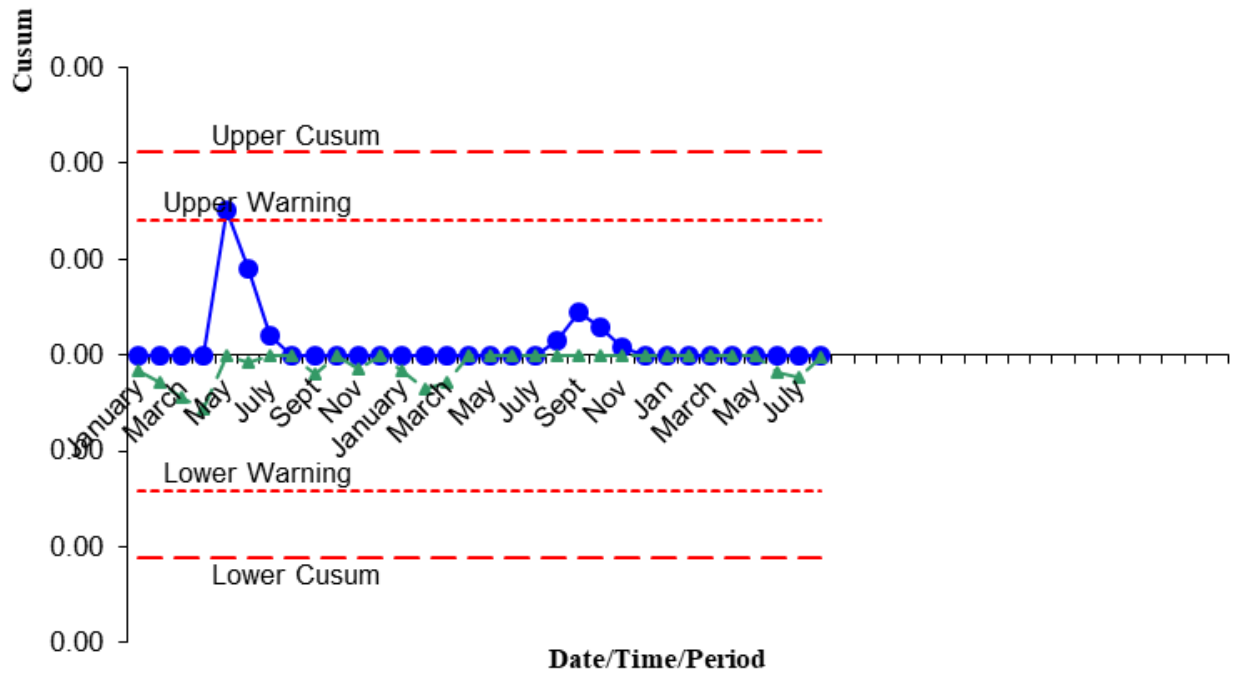

Fig. 7. Variation of Rd over Time in Months (115-C) for Stage 2

From Fig. 7 it is observed that there is stability in the mean of a process as the plotted points fluctuate around the zero points. This could be because of an increase in the temperature ratio from stage 1 to stage 2 . This increase could also be as a result of the NALCO 7330 injected on the tubeside of the heat exchangers. 


\section{CONCLUSION}

From the previous analysis of the thermal performance of the heat exchanger units, it is pertinent to justify that the performance effectiveness of the heat exchanger is a function of the overall heat transfer coefficient, the heat duty and the temperature of the cold fluid.

From Tables 1 and 2 it is observed that the fouling factor reduce in the second stage of the assessment process as the pressure reduces. It is therefore important to note that the dirt factor of the two heat exchangers is a function of the overall heat transfer coefficient and pressure drop in the tube of the heat exchanger units.

The following recommendations are made:

1) The use of a statistical control technique should be employed in assessing the thermal performance of heat exchanger units to monitor small changes during production process and to help ascertain the actual time fouling begins.

2) As a measure to mitigate the occurrence of fouling in the heat exchanger units, it is necessary to inject the tubes of the heat exchanger with NALCO fluid so as to reduce the pressure drop.

3) Further research should be carried out to determine the heat transfer behaviour of Nano-particles on heat exchanger and its effect on pressure drop.

\section{ACKNOWLEDGMENT}

We wish to thank the Lord, God Almighty for his grace and mercies He has shown from the beginning of this research up to now. We are also grateful to the Head of Department, Mechanical Engineering, Rivers State University, Prof. J. I. Sodiki for his understanding, guidance, constructive criticisms, patience and encouragement. Thanks also go to all the lecturers and staff of the Department of Mechanical Engineering for their inputs from the beginning of the research up till now.

\section{REFERENCES}

[1] Bhatt, D. \& Javhar, P.M. (2014).Shell-and-Tube Heat Exchanger Performance Analysis. International Journal of science and technology, 9(3), $1872-1881$.

[2] Christian, B., Alex, P., \& Sara, B. (2002).Heat Exchange System for Reforming in an Ammonia Process.

[3] Gudmundsson, O., Palsson, O.P., Palsson, H., \& Jonsson, G.R (2011). Comparison ofFouling Detection Between A Physical Method And Black Box Model. Proceedings of International Conference on Heat Exchanger Fouling and Cleaning-2011.

[4] Hasanuzzanman, M. Saidu, R. \& Rahim, N. A. (2011).Effectiveness enhancement of Heat Exchangers by using Nano-fluids.IEEEfrist Conference on clean Energy and technology, 25, 98 - 108.

[5] Hindelang, M.J., Palazzolo, J., \& Rebertson, M., (2012)."Condensers" Encyclopedia of Chemical Engineering Equipment, University Michigan.

[6] Kalpesh, P. O. \& Chopra, M. (2013).Performance analysis of cross counter flow shell and tube heat exchanger by experimental investigation mathematical modeling.International Journal of Engineering Research and Technology, 2, 7, 271-276.

[7] Kern, D. Q. (1965), Process Heat Transfer, 7th Edition, McGraw-Hill, Inc. New York.

[8] Lebele-Alawa, B.T. \&Ohia, I. O. (2013). Performance Evaluation of heat Exchanger, in Polyethylene Plant. International Journal of Engineering and Technology Innovation, 8(1). 49 - 57.

[9] Nalco Company (2011). Safety data sheet Nalco(A) 7330-Lellog Registration systems..

[10] Norrie, B. (2010). Heat Transfer: Principles \& Equipment-Factors Affecting Heat Transfer.

[11] Rajput, P.K (2003). Heat and Mass Transfer. Ram Nagar, New Delhi, S. CHAND \& COMPANY LTD. Chapter 10, 563-654.

[12] Rao V.R \&Savsani, V.J (2012). Mechanical Design Optimization using Advance Optimization Tecniques. Springer London Heidelberg. Springer Publisher. DOI:10.1007/978-1-2748-2. Chapter 7.201-210.

[13] SPC for Excel (2014), Statistical process control publications by category from SPC for Excel.

[14] Sabri, A. (2006), Process Engineering Manual: Heat Exchanger Monitoring.

[15] Serth, R.W (2007). Process Heat Transfer: Principles and Applicatins. Kingsville, Taxas. Elsevier Science \& Technology Books - Publisher. Chapter 3.86-115. 